\title{
Cell-free Directed Evolution of a Protease in Microdroplets at Ultrahigh Throughput
}

Josephin M. Holstein, ${ }^{1}$ Christian Gylstorff, ${ }^{1,2}$ \& Florian Hollfelder ${ }^{1 *}$

\footnotetext{
${ }^{1}$ Department of Biochemistry, University of Cambridge, 80 Tennis Court Road, Cambridge, CB2 1GA, UK

2 Present address: Novozymes A/S. Krogshoejvej 36, 2880 Bagsvaerd, Denmark
}

\section{Contents}

S1. General Information and Procedures

S2. Supplementary Figures and Tables

S6

S3. References

S16 


\section{S1. General Information and Procedures}

\section{Chemicals and Materials}

The materials and oligonucleotides used were purchased from Sigma Aldrich (St. Louis, Missouri, USA) unless otherwise noted. Fluorinated oil HFE-7500 was purchased from 3M Novec and 008Fluorosurfactant from Ran Biotechnologies. The fluorogenic EnzChek casein substrate was obtained from ThermoFisher Scientific.

\section{Library construction using Slonomics ${ }^{\circledR}$ for performing directed evolution in droplets}

Six different Savinase ${ }^{\circledR}$ libraries have been generated via a ligation-based strategy for chemical gene synthesis based on the Sloning building block technology $\left(\right.$ Slonomics $\left.^{\circledR}\right) .{ }^{1}$ Six loops of the Savinase ${ }^{\circledR}$ gene consisting of 9-11 amino acids have been randomized. The following amino acid positions have been randomized for each library: Lib-1 $=53-63$, Lib-2 $=94-104$, Lib-3 $=124-134$, Lib-4 = 152-163, Lib-5 = 181-191 and Lib-6 = 209-219. 73\% wildtype are maintained in each position. The numbering of amino acid positions corresponds to that of the subtilase BPN' sequence. ${ }^{2}$ All six linear libraries were equipped with a T7 promotor and a ribosome binding-site (RBS) in front of the Savinase ${ }^{\circledR}$ gene. Each library was amplified using Sav-pUC19t primer pair (for: gttgtaaaacgacggcca, rev: ctgtgtgaaattgttatccgc), 5'-phosphorylated using T4 polynucleotide kinase (NEB) followed by circularization using T4 DNA ligase (NEB). Circularised genes were gel-purified and the concentration determined using a Nanodrop 2000 (Thermo Fisher Scientific, USA).

\section{Chip design and microfluidic device fabrication}

The designs for the poly(dimethyl)siloxane (PDMS) chip devices were prepared with CAD software (DraftSight, Dassault Systems). The corresponding CAD files can be downloaded from http://openwetware.org/wiki/DropBase. The devices were fabricated by standard soft lithography procedures using a high-resolution acetate mask (Microlithography Services Ltd.) and SU-8-2025 photoresist patterning. ${ }^{3,4}$ PDMS monomer and curing agent were mixed at a ratio 10:1 and then poured onto the lithographic plate before degassing. After PDMS solidification $\left(65^{\circ} \mathrm{C}, 4 \mathrm{~h}\right)$, PDMS was activated by exposure to an oxygen plasma and devices were sealed onto a microscope glass slide (or cover slip (thickness: $0.13 \mathrm{~mm}$ ) for the sorting chip). Hydrophobic modification of the channels surface was achieved by injecting a solution of $1 \%(\mathrm{v} / \mathrm{v})$ trichloro $(1 \mathrm{H}, 1 \mathrm{H}, 2 \mathrm{H}, 2 \mathrm{H}$-perfluorooctyl)silane (Sigma) in HFE-7500 oil into the channels.

\section{Flow-focusing generation of water-in-oil picolitre droplets to perform rolling circle amplification}

Water-in-oil droplets were generated at high rates $(\sim 4 \mathrm{kHz})$ using a microfluidic double flow-focusing device (height: $30 \mu \mathrm{m}$; width: $30 \mu \mathrm{m}$ at the flow-focusing junction; see SI Figure S15a) bearing three inlets. The microfluidic device was operated with syringe pumps (Nemesys or Cetoni) and gas-tight glass syringes (SGE) which were connected to the chip via fine pore PTFE tubing (ID $0.38 \mathrm{~mm}$, OD $1.09 \mathrm{~mm}$, Smith Medical). Two aqueous streams were mixed at the first junction and dispersed into the fluorinated oil HFE-7500 (3M) containing $2 \% \mathrm{w} / \mathrm{w}$ fluorosurfactant-008 at the second junction. The two aqueous phases used to generate the droplets contained reagents to perform RCA in droplets. RCA amplifications were performed using the commercial Illustra GenomiPhi V2 DNA Amplification Kit (GE Healthcare, Saclay, France). Briefly, the DNA is heat-denatured then cooled in sample buffer containing random hexamers that non-specifically bind to the DNA. In a separate tube the second solution is prepared containing DNA polymerase $\left(1 / 5\right.$ diluted with $\left.\mathrm{ddH}_{2} \mathrm{O}\right)$, additional random hexamers, nucleotides, salts and buffers. The flow rates for oil, and the two aqueous solutions were 28 $\mu \mathrm{L} / \mathrm{min}, 2 \mu \mathrm{L} / \mathrm{min}$, and $2 \mu \mathrm{L} / \mathrm{min}$, respectively, resulting in droplet volumes of about $14 \mathrm{pL}$. To obtain the required plasmid/droplet ratio after compartmentalization it was calculated that, by using 714,286 plasmids, $10 \%$ of the generated droplets contain a single plasmid, assuming a Poisson distribution for encapsulation. The droplet generation process was monitored on an inverted microscope (SP981, Brunell Microscopes) equipped with a high-speed camera (Miro eX4, Phantom Research). The generated droplets were collected into an inverted $500 \mu \mathrm{L}$ microcentrifuge tube which was pre-filled with fluorinated oil containing $2 \%$ surfactant. The tube was modified by inserting tubing through access holes at the top and bottom of the microcentrifuge tube. This incubation chamber was sealed with 
adhesive glue (Scotch-Weld PR1500,3M). The generated droplets were incubated at $30^{\circ} \mathrm{C}$ for 6 hours to perform an isothermal amplification of DNA. After amplification the enzyme is heat inactivated for 15 minutes at $65^{\circ} \mathrm{C}$.

\section{Picoinjection of IVTT reagent and casein substrate}

The picoinjector devices were fabricated in PDMS, using the techniques described above, and consist of a droplet spacer and picoinjector (Supplementary Figure S15b). The devices have channel heights between 30 and $35 \mu \mathrm{m}$. Electrodes were made by filling channels with salt solution $(5 \mathrm{M} \mathrm{NaCl}){ }^{5}$ The picoinjector injects fluid by merging the droplets with a pressurized channel containing the reagent. Picoinjection is triggered by an electric field, applied by electrodes connected to a high-voltage amplifier with a voltage output of $1.5 \mathrm{~V}$ at a frequency of $10 \mathrm{kHz}$. This voltage is applied to the electrodes to trigger injection. General flow rates for oil, the droplets and the solution to be injected were $3 \mu \mathrm{L} / \mathrm{min}$, $2 \mu \mathrm{L} / \mathrm{min}$, and $1 \mu \mathrm{L} / \mathrm{min}$, respectively, resulting in injected volumes of 15 to $30 \mu \mathrm{pL}$. In vitro transcripction/translation (IVTT) in droplets was performed using the PURExpress In Vitro Protein Synthesis Kit (New England Biolabs, Hitchin, United Kingdom), according to the manual provided by the supplier. As a fluorogenic protease substrate the EnzChek Protease Assay Kit (Invitrogen, Carlsbad, United States) was used. For picoinjection in droplets the substrate was diluted 25 -fold with $\mathrm{ddH}_{2} \mathrm{O}$, to give an approximate concentration of $40 \mu \mathrm{g} / \mathrm{mL}$. After injection of the fluorogenic casein EnzChek substrate the droplets were incubated in darkness for up to three days.

\section{Fluorescence-activated droplet sorting}

Water-in-oil droplets were re-injected into the sorting device (SI Figure S15c) at $0.5 \mu \mathrm{L} / \mathrm{min}$ and spaced out with oil $(0.5 \% \mathrm{w} / \mathrm{v} 008$-FluoroSurfactant in HFE7500) at $8 \mu \mathrm{L} / \mathrm{min}$. As a result, droplets were sorted at a frequency of $200 \mathrm{~Hz}$. A 488-nm laser was focused $180 \mathrm{~mm}$ upstream of the sorting junction through a 40x microscope objective (UPlanFLN, Olympus) for fluorophore excitation and the emitted fluorescent light was collected and amplified using photomultiplier tubes (H8249, Hamamatsu Photonics). The amplified fluorescence signal was processed by a data acquisition card operating at 38 $\mathrm{kHz}$ (National Instruments, USB-6009) that was linked to a peak detection algorithm, ${ }^{6}$ which recorded fluorescence distributions (LabView 8.2, National Instrument). Hardware triggering was implemented via a voltage comparator (LM339N, Texas Instruments), which compared the voltage readout by the photomultiplier tube with a user-defined arbitrary voltage generated via the acquisition card and doubled using an operational amplifier (LM358N, STMicroelectronics), to generate voltages between 0 and 10 $\mathrm{V}$. A pull-up resistor $(1 \mathrm{kO})$ was used to force the logical high state of the comparator to $5 \mathrm{~V}$ and send the trigger signal to the pulse generator. Whenever the fluorescence peak reached a user-defined voltage threshold, a pulse generator triggered a single square pulse of $50 \mathrm{~ms}$ length and an amplitude of $0.7 \mathrm{Vp}$. This pulse was amplified 1,000-fold by a high voltage amplifier (610E, Trek) and applied to the electrodes on the sorting device. The sorting events were recorded with a fast camera (Phantom V7.2) that was triggered by the voltage comparator, to allow analysis of whether the desired droplets with increased fluorescence were indeed selected after the sort was carried out. Optical inspection of the movies thus recorded provided confirmation that only single droplets were selected for each pulse.

\section{DNA recovery}

Sorted droplets were collected into a $1.5 \mathrm{~mL}$ low DNA retention reaction tube (DNA LoBind, Eppendorf) and de-emulsified by adding $200 \mu \mathrm{L} \mathrm{1H,1H,2H,2H-perfluorooctanol} \mathrm{(97 \% ,} \mathrm{Alfa} \mathrm{Aesar).} 25$ $\mu \mathrm{L}$ of a $2 \mathrm{ng} / \mu \mathrm{L}$ salmon sperm DNA solution (Invitrogen) was added to the collected droplets. The tube was vortexed briefly and centrifuged for $1 \mathrm{~min}$ at $1,000 \mathrm{xg}$. The aqueous layer was transferred to a fresh reaction tube and the oil extraction was repeated twice. $5 \mu \mathrm{L}$ of the aqueous phase were used for PCR amplification $\left(30 \mathrm{~s} 98^{\circ} \mathrm{C}, 25 \times\left(10 \mathrm{~s} 98^{\circ} \mathrm{C}, 30 \mathrm{~s} 55^{\circ} \mathrm{C}, 30 \mathrm{~s} 72{ }^{\circ} \mathrm{C}\right), 300 \mathrm{~s} 72{ }^{\circ} \mathrm{C}\right.$, final hold $\left.4{ }^{\circ} \mathrm{C}\right)$ using the sav-wt-Gibson primer pair

- for: gattacaaaaacatcagccatgggtGCTGAAGAAGCAAAAGAAAAATATTTAATTGG;

- rev: cagtggtggtggtggtggtgctcgagACGCGTTGCCGCTTCTGC).

The PCR product was purified by agarose gel electrophoresis. Isolated DNA was subcloned into the pCri18a plasmid (Addgene) via Gibson-Assembly. ${ }^{7}$ 


\section{Quantification of enrichment of wildtype by quantitative PCR}

To quantify the sorting efficiency, pUC19-sav-wt plasmid was mixed 1:250 with either pHAT-EtsB or pUC-EstB construct expressing the esterase EstB. Droplet generation, picoinjections and FADS were performed as described above. The amount of DNA was determined before and after sorting via quantitative PCR (qPCR). The following two primer pairs were designed that amplify a sequence of 100 nt of each gene and share the same melting temperature $\left(T_{\mathrm{m}}=55^{\circ} \mathrm{C}\right)$ and $\mathrm{GC}$ content $(55 \%)$ : Sav-qPCRfor gcaatcggtaccatggggaa; Sav-qPCR-rev tccetgtatcgaggacagca; EstB-qPCR-for gtatccgcgtagcetggaaa; Estb-qPCR-rev ccaaaccggtgcataatggc. $0.5 \mu \mathrm{M}$ of each primer were mixed with 1x SensiMix SYBR green (Bioline) in a total volume of $25 \mu \mathrm{L}$. Quantitative PCR experiments were performed in duplicate in a CFX Connect (Bio-Rad) real-time PCR cycler. The cycling parameters were: initial DNA denaturation at $95{ }^{\circ} \mathrm{C}$ for $10 \mathrm{~min}, 40$ cycles $\left(95^{\circ} \mathrm{C}\right.$ for $15 \mathrm{~s} ; 55^{\circ} \mathrm{C}$ for $15 \mathrm{~s} ; 7{ }^{\circ} \mathrm{C}$ for $\left.20 \mathrm{~s}\right)$ followed by a temperature gradient enabling determination of the DNA melting temperature (between $79{ }^{\circ} \mathrm{C}$ and 85 ${ }^{\circ} \mathrm{C}$ ). Reference curves using concentrations $1 \mathrm{ng} / \mu \mathrm{L}$ to $0.01 \mathrm{pg} / \mu \mathrm{L}$ plasmid DNA with both sets of primers were obtained with correlation coefficients $\mathrm{R}>0.99$.

\section{Re-screening of hits in $B$. subtilis as a host organism}

Individual colonies of Savinase ${ }^{\circledR}$ variants transformed into $B$. subtilis were picked up and inoculated in 96-deep well plates containing $1 \mathrm{~mL}$ of $2 \mathrm{YT}$ medium supplemented with $5 \mu \mathrm{g} / \mathrm{mL}$ chloramphenicol. The cells were grown at $37^{\circ} \mathrm{C}$ and $600 \mathrm{rpm}$ overnight. $50 \mu \mathrm{L}$ of these overnight cultures were used to inoculate $1200 \mu \mathrm{L}$ of $2 \mathrm{YT}$ medium and grown for three hours at $37^{\circ} \mathrm{C}$. These cultures were induced with $500 \mu \mathrm{M}$ IPTG and further incubated at $20^{\circ} \mathrm{C}$ for $18 \mathrm{~h}$. After recombinant production and secretion of proteins, cultures were centrifuged at $4000 \mathrm{xg}$ for 30 minutes at $4{ }^{\circ} \mathrm{C} .100 \mu \mathrm{L}$ of the supernatant was assayed for activity by adding $0.2 \mu \mathrm{L}$ EnzChek substrate $(1 \mathrm{mg} / \mathrm{mL}$ in PBS) and $10 \mathrm{mM}$ calcium chloride in reaction buffer (100 mM Tris-HCl, $2 \mathrm{mM}$ calcium chloride, 2.5\% Triton (v/v), pH 9). Fluorescence $\left(\lambda_{\mathrm{ex}}=485 \mathrm{~nm} ; \lambda_{\mathrm{em}}=515 \mathrm{~nm}\right)$ was measured over time using a plate reader. Variants showing fluorescence three times higher than standard deviation compared to wildtype were selected for sequencing and further testing.

\section{Protein production and purification}

For recombinant production of Savinase ${ }^{\circledR}$ and identified hits from the re-screening, the genes were amplified by PCR with Phusion High-Fidelity DNA Polymerase (ThermoFisher Scientific, F530L) using the sav-wt-Gibson primer pair. The amplified fragments were inserted into pCri18-a plasmid by Gibson-Assembly. The recombinant protein will be equipped with signal peptide for secretion and a Cterminal $6 \times$ His tag for subsequent purification. 168 Marburg B. subtilis strain was transformed with pCri18a derivatives. The recombinant $B$. subtilis strains were grown in 2 YT medium supplemented with $5 \mu \mathrm{g} / \mathrm{mL}$ chloramphenicol at $37^{\circ} \mathrm{C}$ until an $\mathrm{OD}_{600}$ of 1 was reached. After induction by adding $0.5 \mathrm{mM}$ IPTG, the culture was further incubated at $20^{\circ} \mathrm{C}$ for $18 \mathrm{~h}$. The culture was centrifuged $(13,000 \times \mathrm{g}, 10$ min, $4{ }^{\circ} \mathrm{C}$ ) and supernatant applied to a Ni-NTA column equilibrated with buffer A containing $50 \mathrm{mM}$ Tris-HCl, $150 \mathrm{mM} \mathrm{NaCl}$ and $50 \%$ glycerol (pH 8). After washing with 20 column volumes buffer A containing $20 \mathrm{mM}$ imidazole, the bound proteins were eluted with $500 \mathrm{mM}$ imidazole in buffer $\mathrm{A}$. The enzyme in the elution buffer was further changed to buffer A by an Amicon ultra-4 centrifugal filter device (Millipore, USA) using the appropriate cut-off based on their molecular weight and then stored at $-20{ }^{\circ} \mathrm{C}$. Protein production was confirmed by sodium dodecyl sulfate polyacrylamide gel electrophoresis and the concentration was determined by active site titration. Activity was tested by incubating $1 \mu \mathrm{M}$ enzyme with $0.2 \mu \mathrm{L}$ EnzChek substrate $(1 \mathrm{mg} / \mathrm{mL})$ and $10 \mathrm{mM}$ calcium chloride in reaction buffer buffer (100 $\mathrm{mM}$ Tris-HCl, $2 \mathrm{mM}$ calcium chloride, 2.5\% Triton (v/v), $\mathrm{pH} 9)$. Fluorescence $\left(\lambda_{\mathrm{ex}}=485 \mathrm{~nm} ; \lambda_{\mathrm{em}}=515 \mathrm{~nm}\right)$ was measured over time using a plate reader. Initial velocities and end-point fluorescence was determined and compared to wildtype activity. 


\section{Active site titration}

For the active site titration, a $10 \mathrm{mM}$ solution of phenylmethylsulfonyl fluoride (PMSF) in 2-propanol was freshly prepared. $0.25 \mu \mathrm{L}$ enzyme was mixed with 0-2 mM PMSF in reaction buffer (100 mM Tris$\mathrm{HCl}, 2 \mathrm{mM}$ calcium chloride, $2.5 \%$ Triton (v/v), $\mathrm{pH} 9)$. After a short incubation time the total content of enzyme was assayed for activity by adding $125 \mu \mathrm{M} \mathrm{N}$-Succinyl-Ala-Ala-Pro-Phe $p$-nitroanilide (sAAPF-pNA) substrate. The released $p$-nitroanillide can be measured by spectro-photometrical quantification at $410 \mathrm{~nm}$ and initial steady-state velocities determined. The residual activity was plotted versus the amount of PMSF and a line was fitted through the data points. The amount that is required for complete inactivation corresponds to the number of active sites.

\section{Generation of a shuffled library using staggered extension process (StEP)}

A shuffled library of identified hits was generated via StEPs in vitro recombination following a procedure described in the literature. ${ }^{8}$ Briefly, $20 \mathrm{ng}$ of mixed plasmid DNA were used as templates and mixed in a final volume of $50 \mu \mathrm{L}$ with $0.15 \mu \mathrm{M}$ of the sav-wt-Gibson primer pair, 1x PCR buffer, 200 $\mu \mathrm{M}$ dNTP mix, $1.5 \mathrm{mM} \mathrm{MgCl}_{2}$ and $2.5 \mathrm{U}$ Taq polymerase. The PCR-cycler was programmed for 100 cycles using the following parameters: $94{ }^{\circ} \mathrm{C}$ for $30 \mathrm{~s}$ (denaturation) and $55^{\circ} \mathrm{C}$ for $17 \mathrm{~s}$ (annealing/extension). The PCR product was purified by agarose gel electrophoresis. Isolated DNA was further amplified by using the Sav-Sh-Lib-pHAT primer pair (for: tcaccatcaccatcacaaca ct atg gctgaagaagcaaaagaaaaa; rev: gtgacactatagaatactca TTA ACG CGT TGC CGC TTC TGC GTT) and subcloned into the pHAT plasmid providing a T7 promotor and RBS for IVTT performance in picolitre droplets. 


\section{S2. Supplementary Figures and Tables}

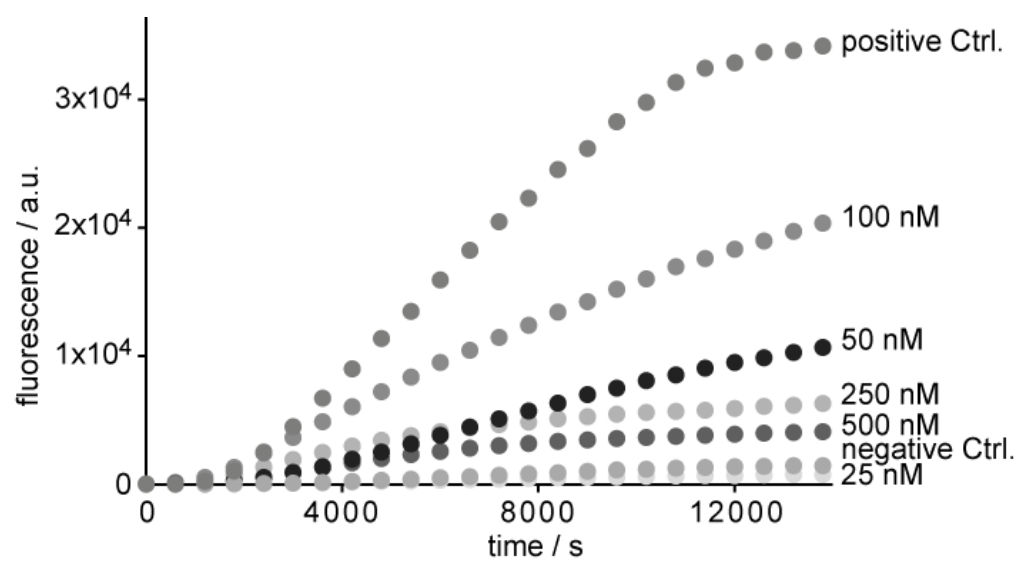

Figure S1. In vitro expression of green fluorescent protein (GFP) using IVTT after DNA amplification with different concentrations of phi29 DNA polymerase. pUC19-GFP plasmid DNA (6 pg/ $\mu \mathrm{L})$ with different concentrations of phi29 DNA polymerase $(500-25 \mathrm{nM})$ and remaining RCA reagents to perform RCA for 3 hours at $30^{\circ} \mathrm{C}$. After addition of IVTT components, GFP expression was monitored over time in a plate reader measuring fluorescence $\left(\lambda_{\mathrm{ex}}=480 \mathrm{~nm} ; \lambda_{\mathrm{em}}=530 \mathrm{~nm}\right) .50 \mathrm{ng} / \mu \mathrm{L} \mathrm{pUC} 19-\mathrm{GFP}$ was used as a positive control ('positive Ctrl.').

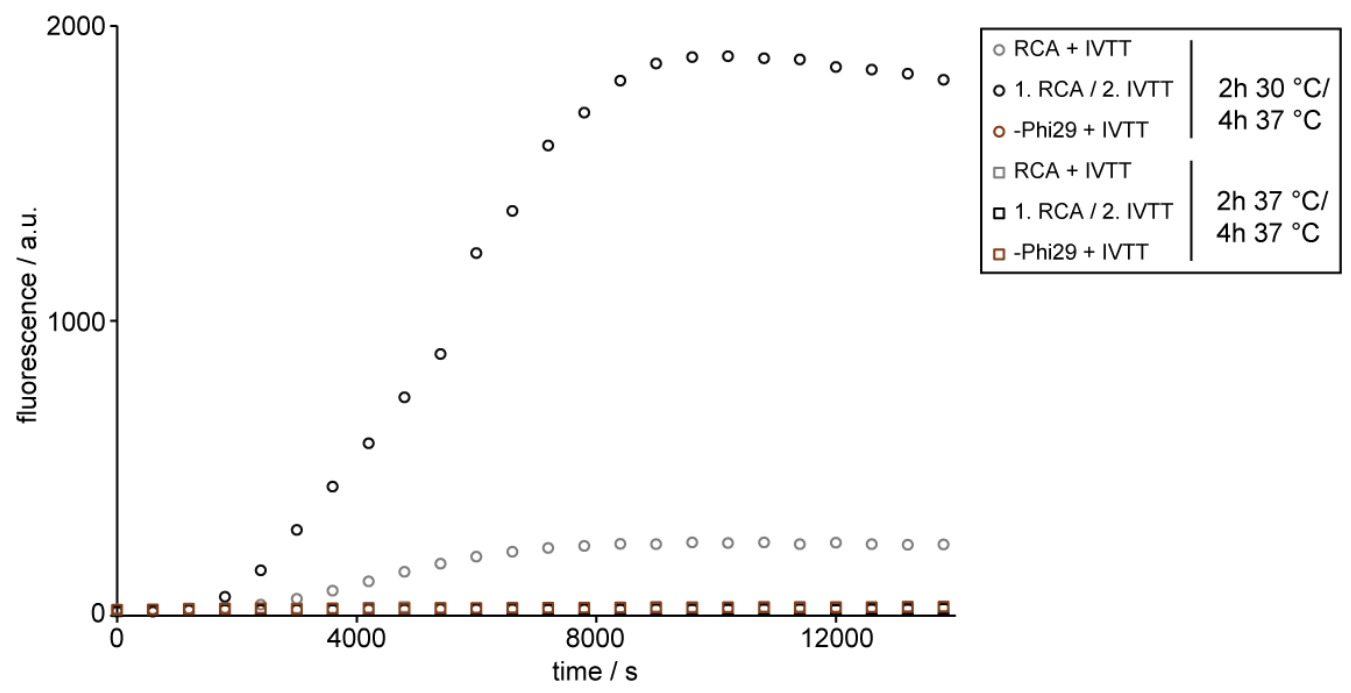

Figure S2. RCA is inhibited by IVTT reagents. RCA was performed by incubating pUC19-GFP plasmid DNA $(6 \mathrm{pg} / \mu \mathrm{L})$ with $\Phi 29$ DNA polymerase $(100 \mathrm{nM})$ in presence of IVTT reagents for 2 hours at 30 ${ }^{\circ} \mathrm{C}$ or $37^{\circ} \mathrm{C}$ (RCA + IVTT), respectively. As control experiments the IVTT reagents were added after performance of RCA (1. RCA/2. IVTT) and a mixture of plasmid DNA without $\Phi 29$ DNA polymerase was incubated with IVTT (-Phi29 + IVTT). In vitro expression of GFP was monitored over time in the plate reader measuring fluorescence $\left(\lambda_{\mathrm{ex}}=480 \mathrm{~nm} ; \lambda_{\mathrm{em}}=530 \mathrm{~nm}\right)$ for 4 hours at $37^{\circ} \mathrm{C}$. 


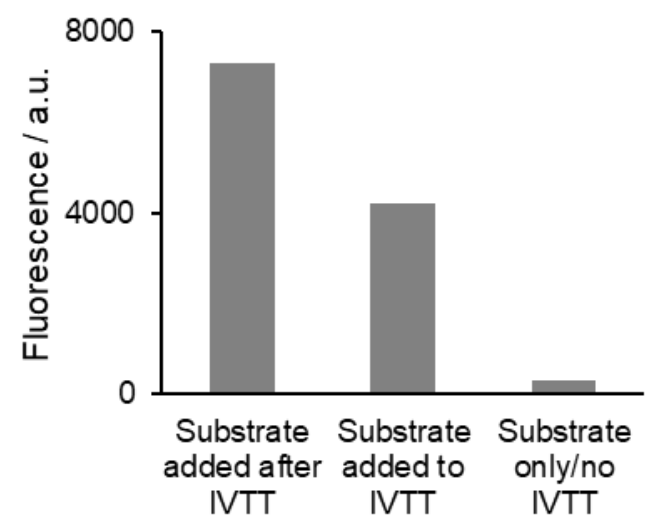

Figure S3. Addition of EnzChek substrate after expression of sav-wt using IVTT results in higher fluorescent signal. pUC19-sav $(10 \mathrm{ng} / \mu \mathrm{L})$ was incubated with IVTT reagents (PURE) either in presence of the fluorogenic EnzChek substrate $(2 \mu \mathrm{g} / \mathrm{mL})$ or without. In latter case the substrate was added after expression of sav-wt performed at $37^{\circ} \mathrm{C}$ for 4 hours. In both cases the fluorescent signal was measured after 12 hours reaction time $\left(\lambda_{\mathrm{ex}}=480 \mathrm{~nm} ; \lambda_{\mathrm{em}}=530 \mathrm{~nm}\right)$.

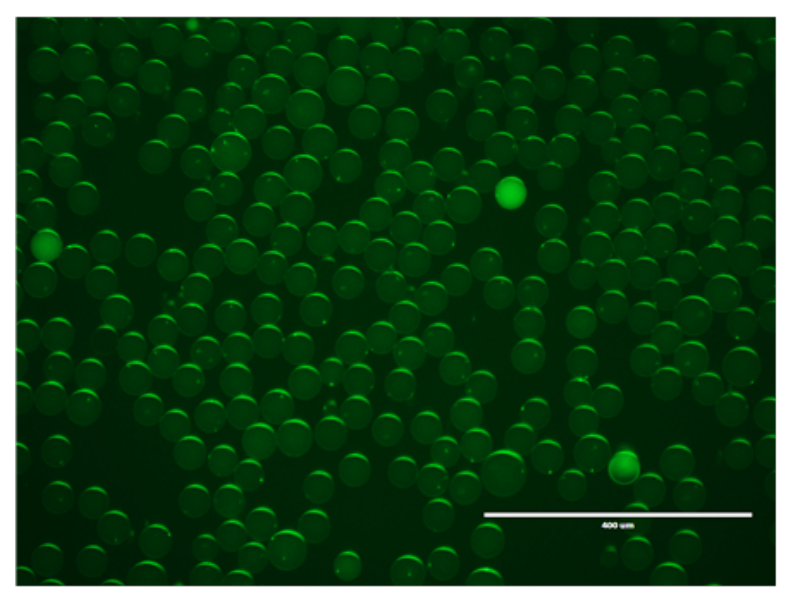

Figure S4. Enzymatic reaction in droplets. Single plasmids of a pUC19-sav-wt were compartmentalized in picolitre water-in-oil droplets $(\lambda=0.1)$ together with RCA reagents. After injecting IVTT components and the fluorogenic casein substrate, microscope images of the droplets were taken. Green fluorescent droplets can be detected showing savinase activity that are surrounded by droplets that lack enzymatic activity, because they are unoccupied. Scale bar: $400 \mu \mathrm{m}$.

Table S1. Enrichment of sav-wt by FADS based on proteolytic activity. For two separate enrichment experiments two sortings each were performed and fluorescent droplets similar to sav-wt activity were collected (see SI Figure S3). Starting ratio of active (sav-wt) to inactive (neg Ctrl.) plasmids were determined by qPCR. The enrichment values $\eta$ were determined after two different equations described in the literature. ${ }^{9,10}$ According to Baret et al. the enrichment $\eta$ after one round of sorting was developed as a function of $\lambda$ (the occupancy based on a Poisson distribution) where $\varepsilon 0$ is the initial ratio of active to inactive genes and $\lambda$ is the initial mean number of plasmids per droplet. The enrichment $\eta$ is defined as the ratio of $\varepsilon 1$ after sorting to $\varepsilon 0$ before sorting. Following Zinchenko et al. the enrichment $\eta$ ' was determined by dividing the percentage of positives after sorting $\left(\varepsilon 1^{\prime}\right)$ by that before sorting $(\varepsilon 0)$. 


\begin{tabular}{|c|c|c|c|c|c|c|c|c|c|}
\hline \multirow[b]{2}{*}{$\lambda$} & \multirow[b]{2}{*}{$\varepsilon 0$} & \multicolumn{2}{|c|}{ Number of droplets } & \multicolumn{2}{|c|}{ Number of plasmids $N$} & \multicolumn{2}{|c|}{ Baret et al. } & \multicolumn{2}{|c|}{ Zinchenko et al. } \\
\hline & & analyzed & selected & sav-wt & neg Ctrl. & & $\eta$ & & \\
\hline 0.1 & 0.004 & 288000 & 105 & 29220 & 22 & 1328 & 332,000 & 0.9992 & 250 \\
\hline 0.1 & 0.004 & 348000 & 71 & 2965 & 42 & 71 & 17,750 & 0.986 & 247 \\
\hline 0.1 & 0.004 & 133000 & 117 & 2178 & 204 & 11 & 2,750 & 0.914 & 229 \\
\hline 0.1 & 0.004 & 244000 & 120 & 241 & 31 & 8 & 2,000 & 0.886 & 222 \\
\hline
\end{tabular}

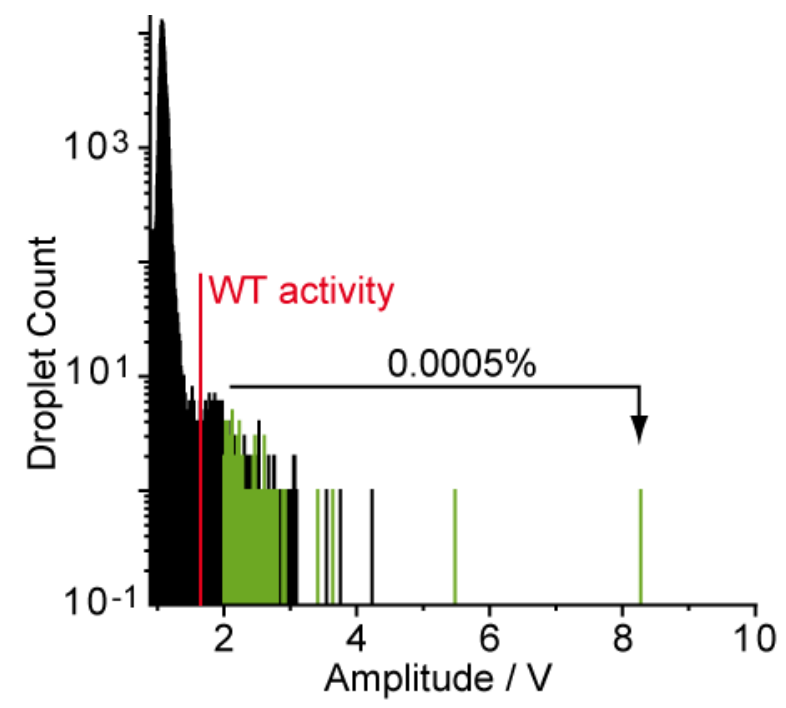

Figure S5. Histogram of 1:250 mixture of droplets containing sav-wt and a negative control gene screened via FADS for proteolytic activity. Droplets were incubated at room temperature in darkness for three days before sorting. The occupancy was $\lambda=0.1$. The sorting gate was set up such that droplets showing increased fluorescence over the population average of a wild-type sample (sav-wt) were selected.

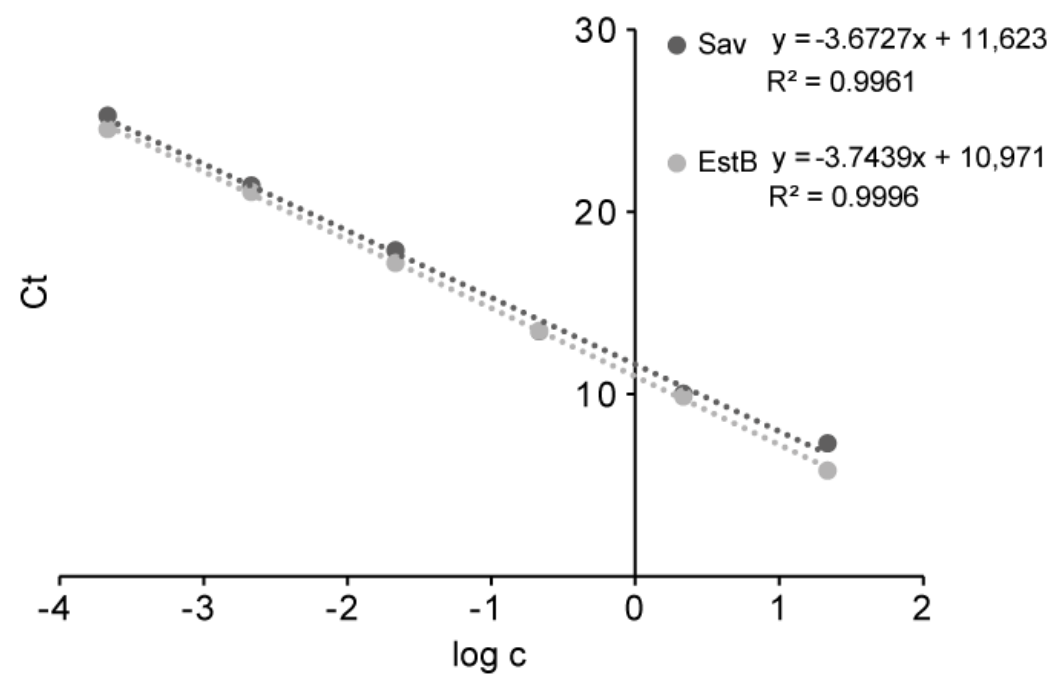

Figure S6. Standard calibration curve for sav-wt and EstB determined via qPCR. Dilution series of pUC-sav-wt and pUC-EstB plasmids were prepared ranging from $1 \mathrm{ng} / \mu \mathrm{L}$ to $0.001 \mathrm{ng} / \mu \mathrm{L}$. After mixing with 1x SensiMix reagent and $0.5 \mu \mathrm{M}$ gene specific primers, qPCRs were performed in duplicate. Calibration curves were generated from the measured $\mathrm{Ct}$ values and standard solution concentrations. Calculated linear regression and correlation coefficients are shown. 


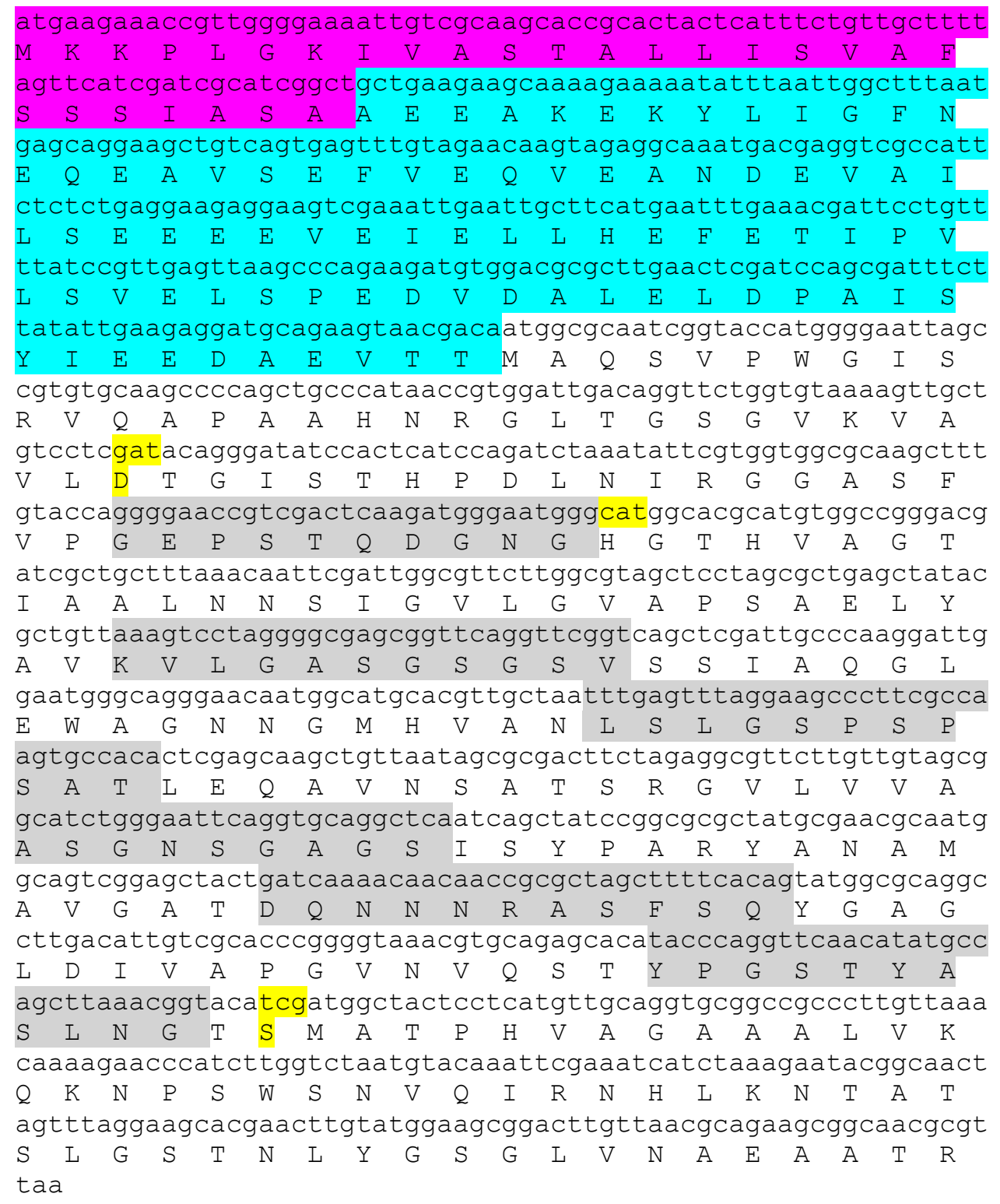

Figure S7. Nucleic and amino acid sequence of Savinase ${ }^{\circledR}$ (pdb: 1SVN). The signal peptide is indicated in purple and the pro-peptide in blue. Amino acids representing the catalytic triad are highlighted in yellow. Amino acids randomized for generating six libraries are highlighted in gray. 


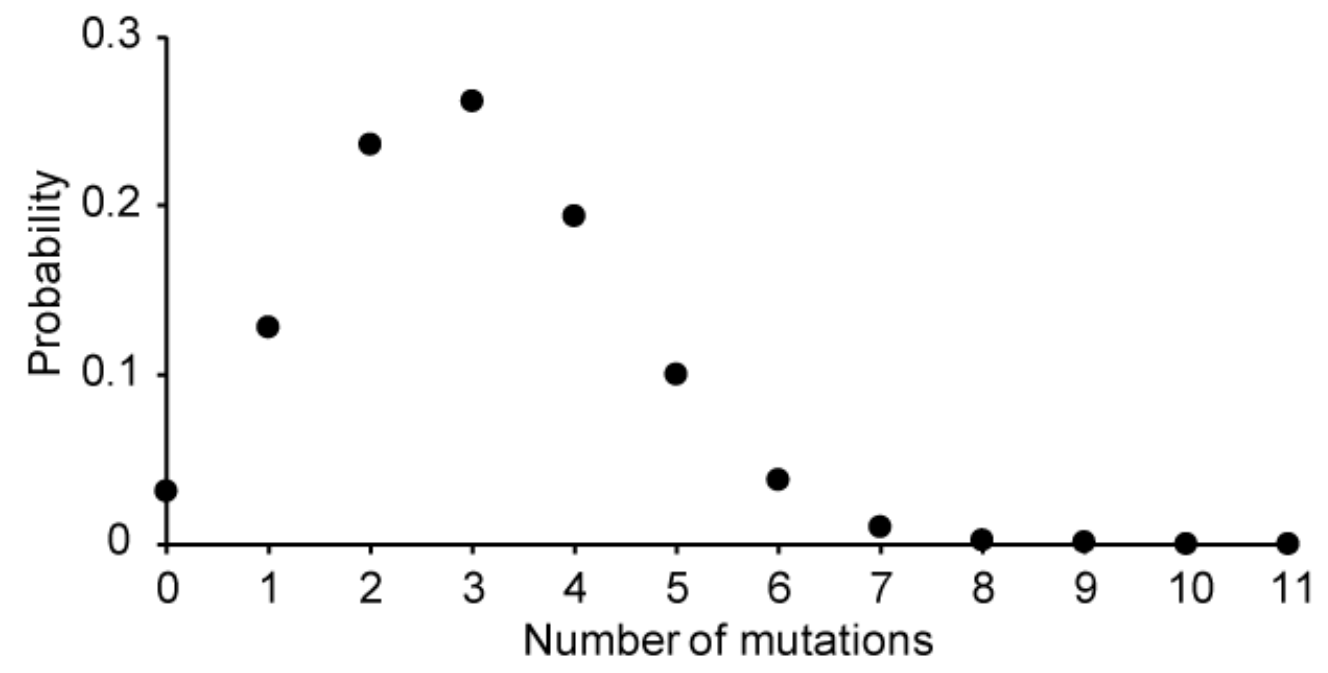

Figure S8. Calculated probability of mutations per gene. The mutational rate per gene generating a library with $73 \%$ chance of wildtype per randomized position is shown. The probability of the number of mutations was calculated using the binominal distribution with $k$ the number of successes in a sequence of $\mathrm{n}=11$ independent experiments having a probability $\mathrm{p}=0.27$ in a non-cumulative distribution function. ${ }^{11}$

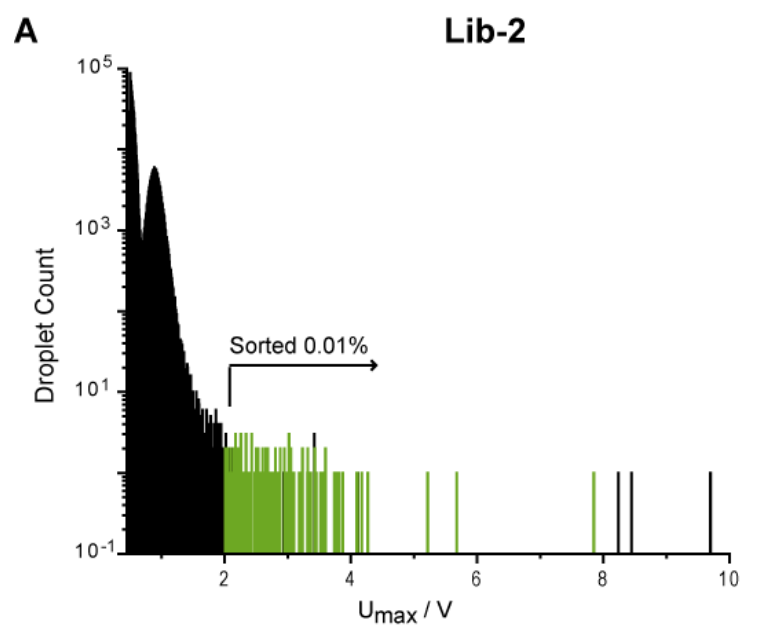

C

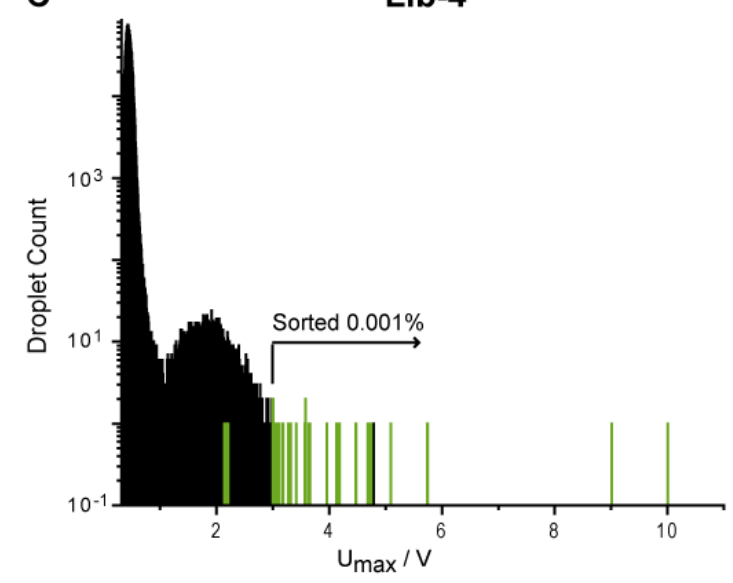

B

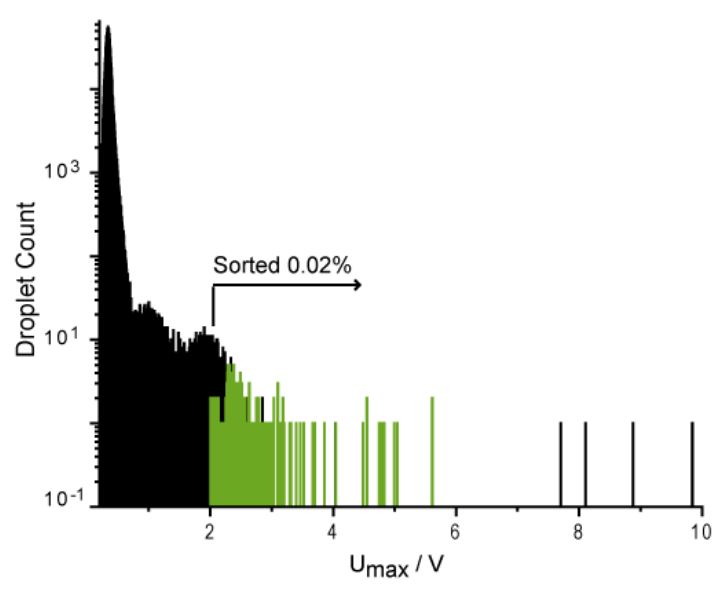

D



Figure S9. Screening of different Savinase ${ }^{\circledR}$ libraries using fluorescence-activated droplet sorting (FADS). A)-D) Histograms of the fluorescence signal distribution of droplets screened for Savinase ${ }^{\circledR}$ activity after three days of incubation at room temperature in darkness. The sorting gate was set up such that droplets showing increased fluorescence over the population average of sav-wt were selected. 
Table S2. Overview of the ultrahigh-throughput screening in microdroplets and re-screening in microtiter plates. Hits were selected for sequencing after showing higher activity compared to sav-wt plus $3 x$ standard deviation in a re-screening performed in 96-well plates using casein substrate and $B$. subtilis for secretion.

\begin{tabular}{cccccc} 
Library & $\begin{array}{c}\text { Droplets } \\
\text { screened }\end{array}$ & $\begin{array}{c}\text { Droplets } \\
\text { sorted }\end{array}$ & $\begin{array}{c}\text { Sequenced } \\
\text { hits }\end{array}$ & $\begin{array}{c}\text { WT } \\
\text { Unique } \\
\text { hits }\end{array}$ \\
\hline Lib-1 & 500,000 & 104 & 18 & 2 & 12 \\
Lib-2 & $1,300,000$ & 130 & 22 & 0 & 7 \\
Lib-3 & $1,100,000$ & 205 & 1 & 0 & 1 \\
Lib-4 & $2,600,000$ & 34 & 1 & 0 & 1 \\
Lib-5 & $4,000,000$ & 218 & 48 & 3 & 28 \\
Lib-6 & $2,600,000$ & 100 & 34 & 2 & 9 \\
\hline Sh-Lib & 100,000 & 80 & 22 & 0 & 5
\end{tabular}
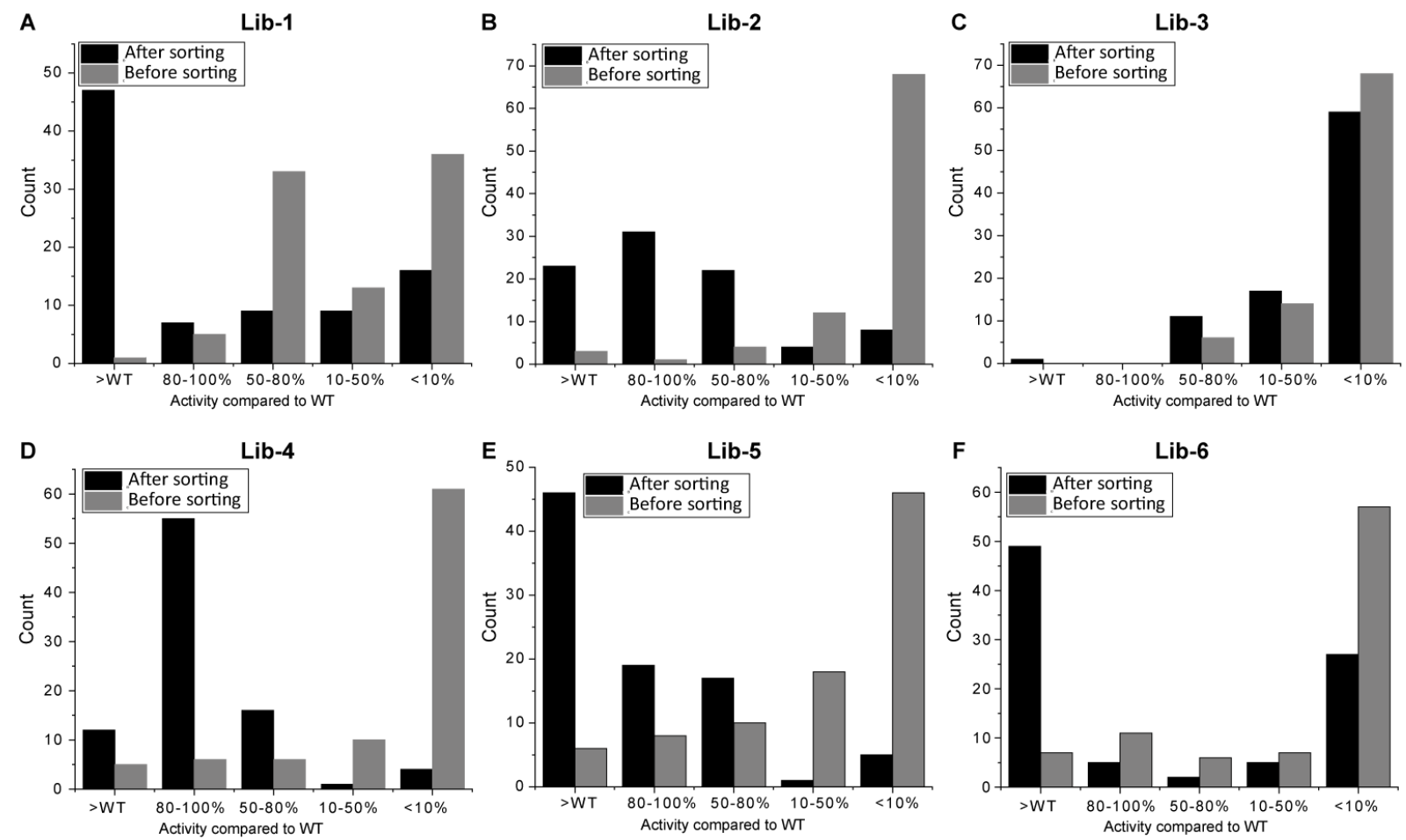

Figure S10. Enrichment of positive hits for each library after FADS. A-F) 88 variants that were randomly picked and secreted by $B$. subtilis from the corresponding original library (before sorting) were assayed against a fluorogenic casein derivative substrate (EnzChek). The data were normalized to the endpoint fluorescence of sav-wt. Activities are separated in higher activity than WT (>WT), 80$100 \%, 50-80 \%$ and $10-50 \%$ wildtype activity as well as variants showing less than $10 \%$ WT activity $(<10 \%)$. 
A
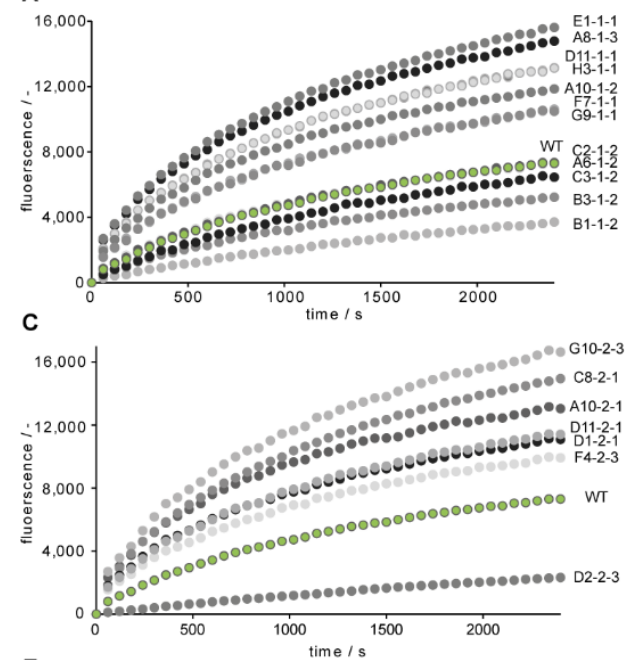

E

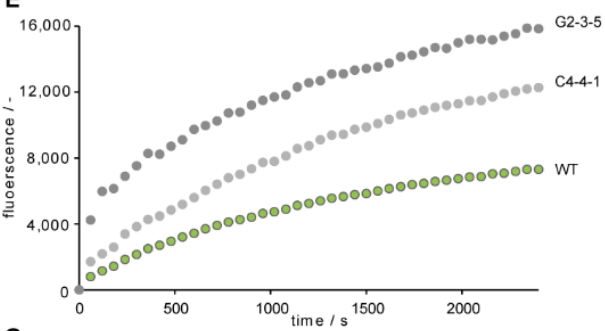

G

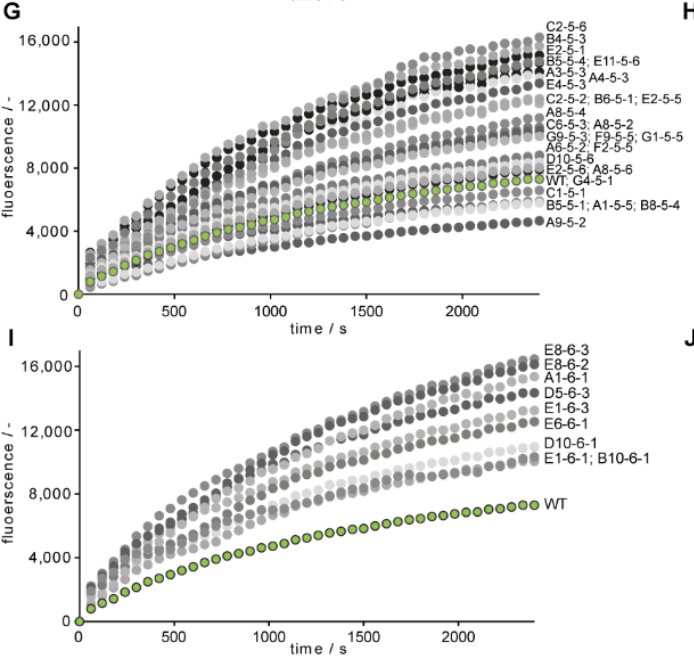

B

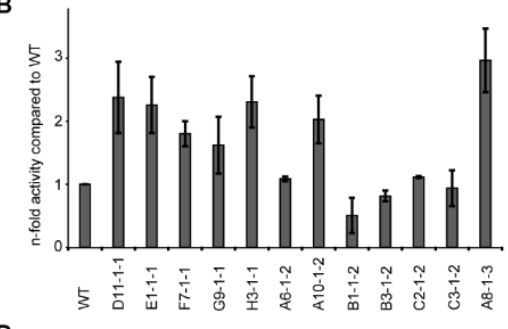

D

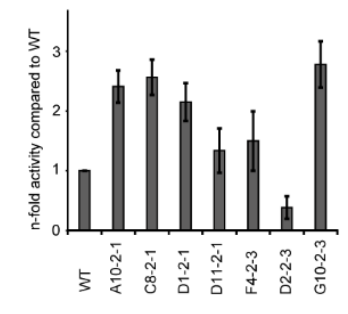

F
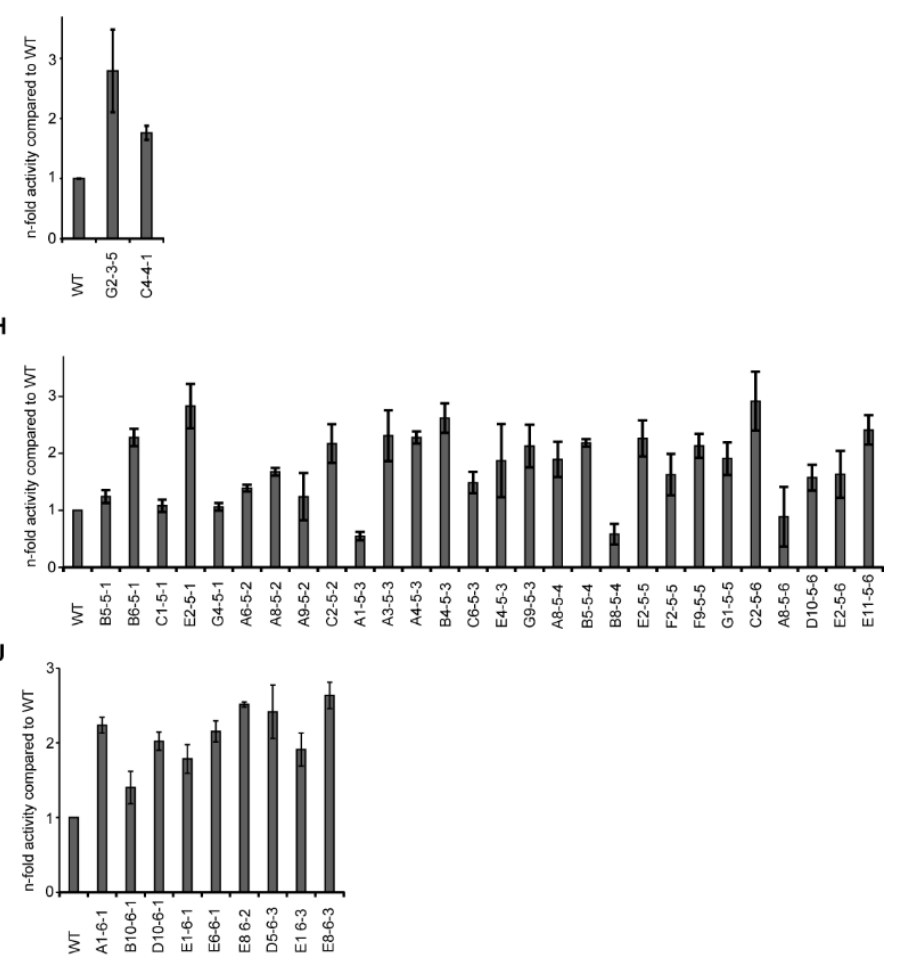

Figure S11. Validation of unique Savinase ${ }^{\circledR}$ hits selected for each library after re-screening in 96-well plates. Purified variants were tested against the fluorogenic casein substrate. A), C), E), G) and I) Timecourses of selected hits in comparison sav-wt. B), D), F), G), and J) The activity for each shuffled variant is plotted relative to that of sav-wt. The names of the variants correspond to the position of a 96-wellplate where it has been identified, the library it originated from and the plate number screened (e.g. D111-1 has been identified at position D11 in lib-1 in the first 96-well-plate screened). 


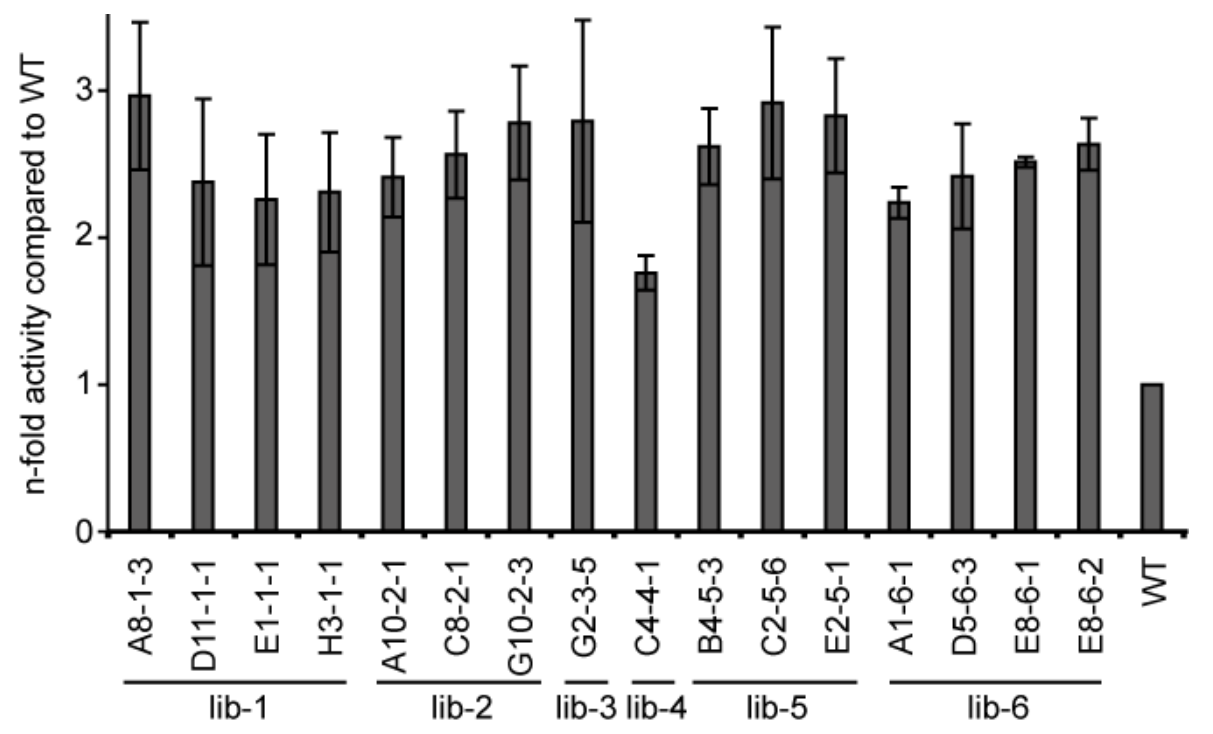

Figure S12. Directed evolution of wt-sav for increased activity against a fluorogenic casein substrate. Activities of selected best variants from each of the six libraries are shown. Variants are plotted relative to that of sav-wt. Data are averages of duplicate values from three independent experiments and two protein purifications.

Table S3. Overview of selected best variants from each library and their mutations compared to the wild type sequence. Mutations are indicated in red. The numbering of amino acid positions corresponds to that of the subtilisin BPN' sequence (Peptidase_S8 (PF00082)).

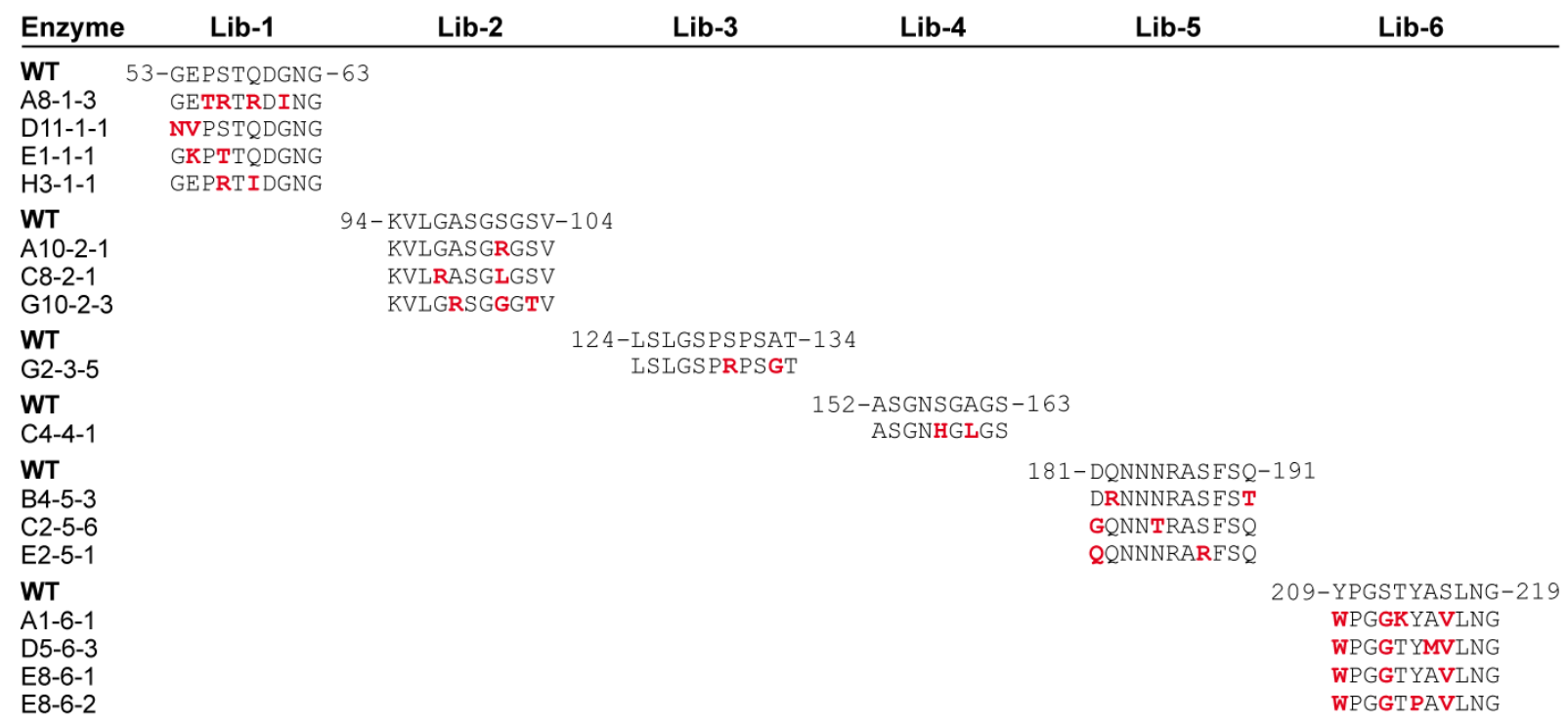




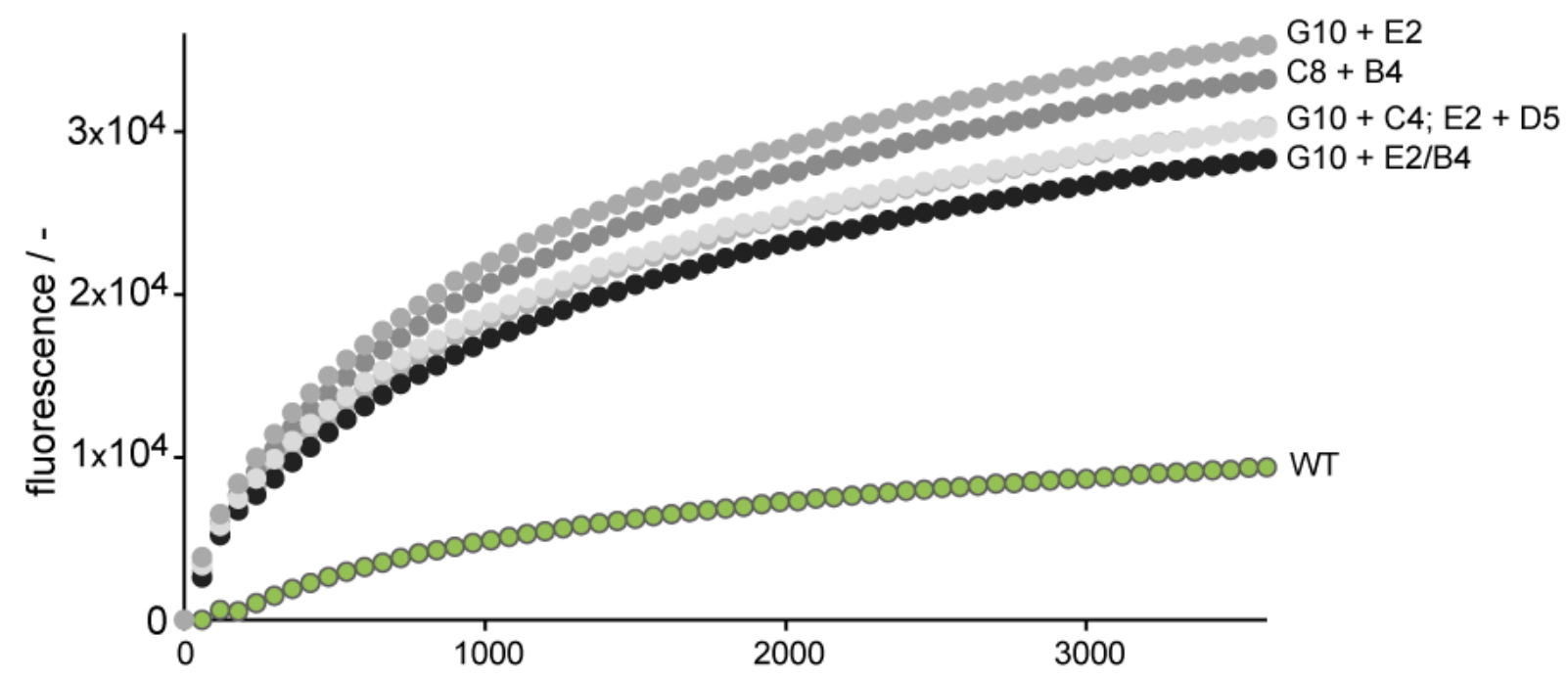

Figure S13. Time-courses of shuffled Savinase ${ }^{\circledR}$ variants identified after re-screening in 96 -well plates. Purified variants were tested against the fluorogenic casein substrate.

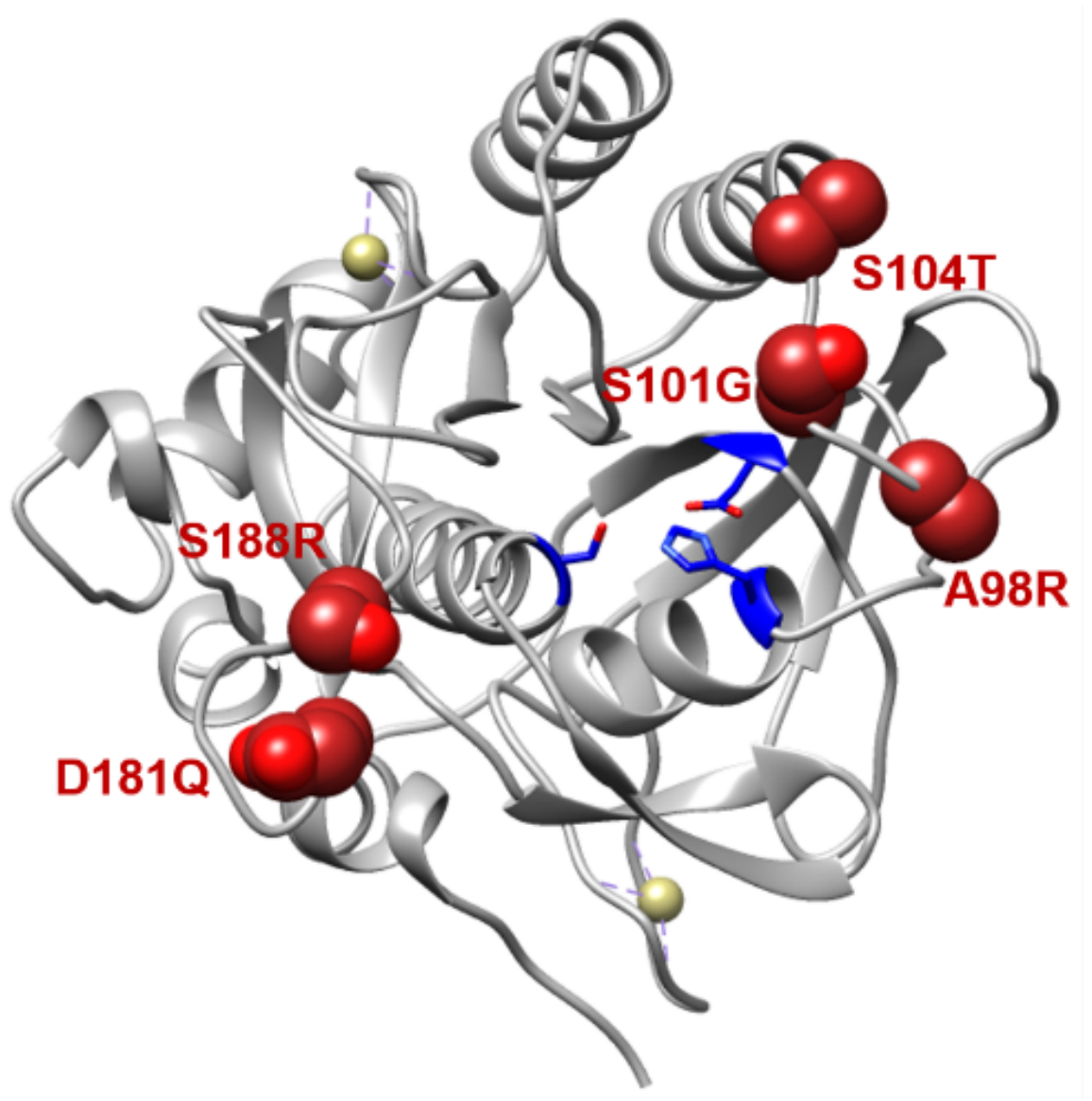

Figure S14. Positions of amino acid substitutions in shuffled variant G10+E2 projected into the structure of mature subtilisin Savinase ${ }^{\circledR}$ (pdb 1svn). Substitutions are indicated by red spheres and residue numbers. Residues D32, H64, and S221 form the catalytic triad in the active site of the protein. 

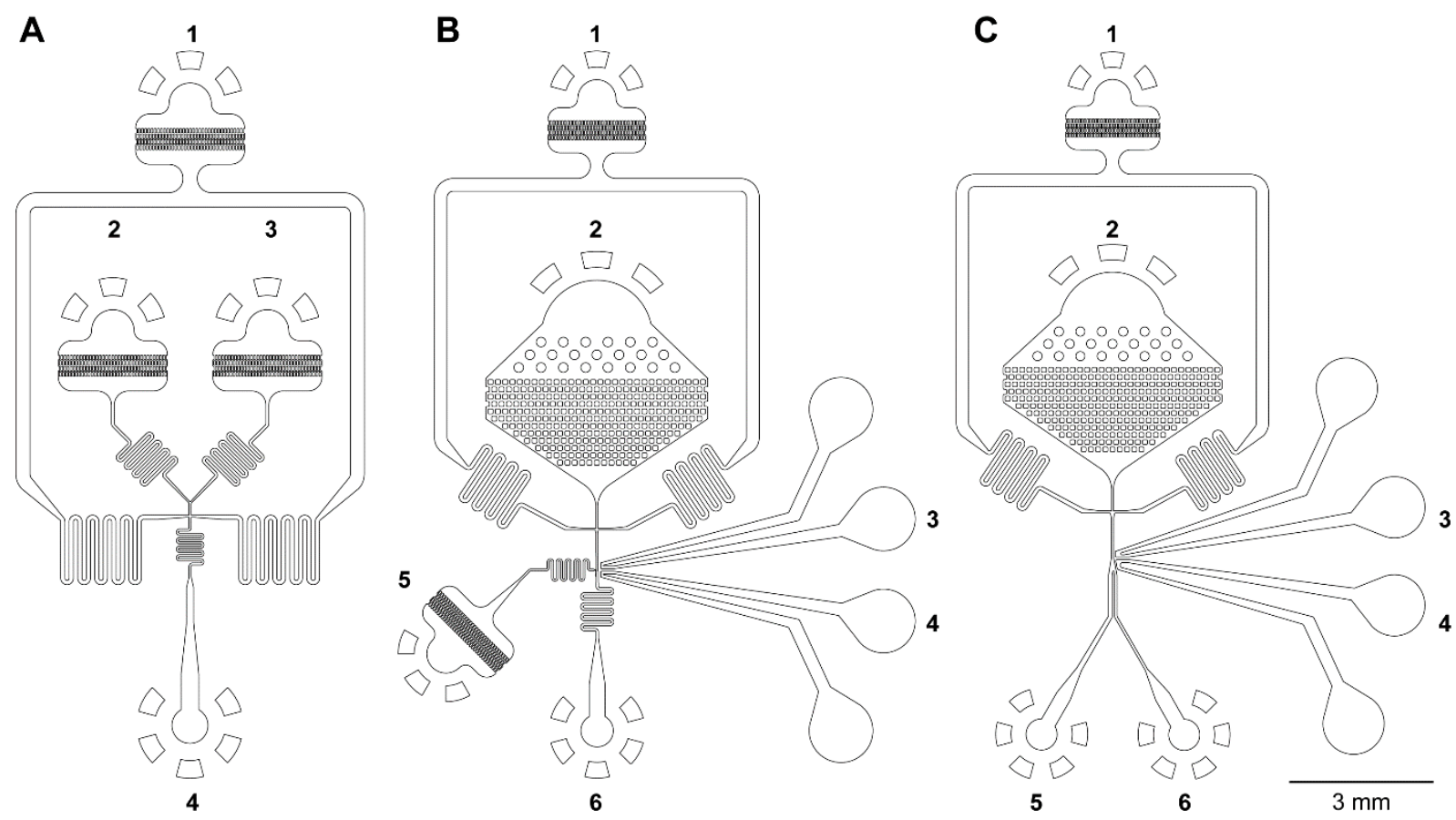

Figure S15. Chip designs. (a) Flow-focusing device for the generation of monodisperse water-in-oil droplets. The two aqueous solutions, containing the plasmids and the RCA reagents were injected from inlet 2 and 3, respectively. Inlet 1 was used for the oil-surfactant mixture. Droplets were collected from outlet 4 . The depth of the droplet generation device is $30 \mu \mathrm{m}$. The channel at the flow-focusing junction is $30 \mu \mathrm{m}$ wide. (b) Microfluidic device for picoinjection. Number $\mathbf{2}$ indicates the inlet for reinjection of the droplet emulsion and number $\mathbf{1}$ for the spacing oil. The picoinjector marked as number $\mathbf{5}$ injects fluid by merging the drops with a pressurized channel containing the reagent. Picoinjection is triggered by an electric field, which is applied by the two electrodes marked as $\mathbf{3}$ and $\mathbf{4}$, respectively. Two different picoinjector devices with channel depths and widths of $30 \mu \mathrm{m}$ and $35 \mu \mathrm{m}$ were used, respectively. The width of the picoinjector nozzle is $10 \mu \mathrm{m}$. (c) Sorting device for the fluorescence-activated screening of droplets. Number $\mathbf{2}$ indicates the inlet for the droplet emulsion and number $\mathbf{1}$ denotes the inlet for the spacing oils. Inlets for the $5 \mathrm{M} \mathrm{NaCl}$ solution for generating a high voltage signal are marked by $\mathbf{3}$ and 4 for ground $[\mathrm{GND}(-)]$ and signal [signal $(+)]$ electrodes, respectively. The outlets of the positive and negative channels are marked by numbers 5 and $\mathbf{6}$, respectively. The depth and width of the sorting channel is $50 \mu \mathrm{m}$. The corresponding $\mathrm{CAD}$ files can be downloaded from http://openwetware.org/wiki/DropBase. 


\section{S3. References}

1. Van den Brulle, J. et al. A novel solid phase technology for high-throughput gene synthesis. Biotechniques 45, 340-343 (2008).

2. Siezen, R. J., De Vos, W. M., Leunissen, J. A. M. \& Dijkstra, B. W. Homology modelling and protein engineering strategy of subtilases, the family of subtilisin-like serine proteinases. Protein Eng. Des. Sel. 4, 719-737 (1991).

3. Mcdonald, J. C., Duffy, D. C., Anderson, J. R. \& Chiu, D. T. Review General Fabrication of microfluidic systems in poly ( dimethylsiloxane ). Electrophoresis 21, 27-40 (2000).

4. Xia, Y. \& Whitesides, G. M. Soft lithography. Annu. Rev. Mater. Sci. 28, 153-184 (1998).

5. Sciambi, A. \& Abate, A. R. Generating electric fields in PDMS microfluidic devices with salt water electrodes. Lab Chip 14, 2605-2609 (2014).

6. Van Loo, B. et al. High-Throughput, Lysis-Free Screening for Sulfatase Activity Using Escherichia coli Autodisplay in Microdroplets. ACS Synth. Biol. 8, 2690-2700 (2019).

7. Gibson, D. G. et al. Enzymatic assembly of DNA molecules up to several hundred kilobases. Nat. Methods 6, 343-345 (2009).

8. Zhao, H., Giver, L., Shao, Z., Affholter, J. \& Arnold, F. Molecular evolution by staggered extension process (StEP) in vitro recombination. Nat. Biotechnol. 16, 258-261 (1998).

9. Baret, J. C. et al. Fluorescence-activated droplet sorting (FADS): Efficient microfluidic cell sorting based on enzymatic activity. Lab Chip 9, 1850-1858 (2009).

10. Zinchenko, A. et al. One in a million: Flow cytometric sorting of single cell-lysate assays in monodisperse picolitre double emulsion droplets for directed evolution. Anal. Chem. 86, 25262533 (2014).

11. Katti, S. K. \& Rao, A. V. Handbook of The Poisson Distribution. Technometrics 10, 412 (1968). 